\begin{tabular}{|c|c|c|}
\hline \multirow{4}{*}{$\begin{array}{r}\text { Case Reports in } \\
\text { Gastroenterology }\end{array}$} & \multirow{2}{*}{\multicolumn{2}{|c|}{ Case Rep Gastroenterol 2019;13:12-16 }} \\
\hline & & \\
\hline & $\begin{array}{l}\text { DOI: 10.1159/000485237 } \\
\text { Published online: January 10, } 2019\end{array}$ & $\begin{array}{l}\text { (c) } 2019 \text { The Author(s) } \\
\text { Published by S. Karger AG, Basel } \\
\text { www.karger.com/crg }\end{array}$ \\
\hline & $\begin{array}{l}\text { This article is licensed under the } \\
\text { International License (CC BY-NC) } \\
\text { Usage and distribution for commerc }\end{array}$ & $\begin{array}{l}\text { nons Attribution-NonCommercial } 4.0 \\
\text { ger.com/Services/OpenAccessLicense). } \\
\text { uires written permission. }\end{array}$ \\
\hline
\end{tabular}

\title{
Duodenal Ulceration following Holmium Laser Lithotripsy
}

\author{
Baldeep Pabla Douglas R. Morgan \\ Division of Gastroenterology, Hepatology, and Nutrition, Vanderbilt University Medical \\ Center, Nashville, TN, USA
}

\section{Keywords}

Peptic ulcer · Duodenal ulcer · Holmium laser lithotripsy · Extracorporeal shock wave lithotripsy · Helicobacter pylori $\cdot$ Nephrolithiasis

\begin{abstract}
The epidemiology of peptic ulcer disease (PUD) has changed considerably in the last several decades. Previously a chronic disease characterized by frequent recurrences with a high rate of surgical interventions, it is now largely a self-limited disease that is medically managed. The role of acid suppression was widely recognized as being important in the pathogenesis of PUD in the 19th century, while it was not until the 1980s and 1990s that the importance of Helicobacter pylori infection was identified. Today, PUD is largely caused by either $H$. pylori infection or nonsteroidal anti-inflammatory drug use. However, other less common etiologies of this disease are becoming more relevant as the prevalence of $H$. pylori decreases and proton pump inhibitor therapy is increasingly common. Here, we report a case of duodenal ulceration following bilateral rigid ureteroscopy with holmium laser lithotripsy.

(C) 2019 The Author(s)

Published by S. Karger AG, Basel
\end{abstract}




\section{Introduction}

Peptic ulcer disease (PUD) is largely caused by either Helicobacter pylori infection or by the use of nonsteroidal anti-inflammatory drugs (NSAIDs). However, other less common etiologies of this disease are becoming more relevant as the prevalence of $H$. pylori decreases and proton pump inhibitor therapy is increasingly common [1,2]. Here, we report a case of duodenal ulceration following bilateral rigid ureteroscopy with holmium laser lithotripsy (HLL).

\section{Case Report}

A 54-year-old man with a past medical history significant for Lynch syndrome complicated by recurrent colorectal cancer (disease free after 2 colonic resections) and recurrent nephrolithiasis presented with epigastric pain following HLL for nephrolithiasis. He initially presented to his local hospital with complaints of flank and back pain 4 days prior to his presentation to our institution. He was diagnosed with recurrent bilateral nephrolithiasis and was noted to have several large kidney stones, including a right distal ureteral stone measuring $1.2 \mathrm{~cm}$ and 3 left-sided stones -2 in his ureter $(1.0 \mathrm{~cm}$ and $8 \mathrm{~mm})$ and a third in the left kidney $(6 \mathrm{~mm})$. He underwent bilateral rigid ureteroscopy with HLL for management of these stones, specifically with a $200-\mu \mathrm{m}$ holmium laser at a setting of $0.3 \mathrm{~J}$ with a pulse rate of $45 \mathrm{~Hz}$ (total time of procedure and energy delivered not reported). Each stone was fragmented, except the most proximal left-sided stone located in the renal pelvis, which was removed without fragmentation. The operative note indicated that there was a significant amount of induration where the distal left ureteral stone had been impacted. He underwent bilateral ureteral stent placement following lithotripsy, with stent removal prior to discharge.

He subsequently developed acute, progressive epigastric pain 1 day prior to admission, noting his pain was worse with oral intake and with movement. He denied nausea, vomiting, fevers, or signs of gastrointestinal bleeding. He denied a history of PUD or acid reflux. He denied chronic use of aspirin, NSAIDs, acid suppressants, illicit drugs such as cocaine, smoking, or use of other medications. He did endorse using 4-6 ibuprofen tablets daily for the 3 days immediately prior to his HLL. The physical exam was notable for borderline hypertension $(144 / 93 \mathrm{~mm} \mathrm{Hg})$ and mild epigastric tenderness to palpation, without any peritoneal signs. White blood cells and liver function tests were within normal limits, with a lipase of 102 units per liter (reference range 8-78 units per liter). The CT scan of his abdomen and pelvis demonstrated significant stranding and inflammatory changes around the descending and transverse portions of the duodenum with mucosal enhancement and foci of gas adjacent to the transverse portion of the duodenum, noted to be either intraluminal or intramural (Fig. 1). The upper endoscopy was notable for 3 non-bleeding, linear duodenal ulcers, with pigmented spots, of the bulb and second duodenum. The largest lesion was $1.0 \mathrm{~cm}$. Diffuse moderately erythematous mucosa was also noted in the second and third segments of the duodenum (Fig. 2). H. pylori IgG serum antibody testing was negative, and serum gastrin was normal. The duodenal biopsies were notable for focal inflammation with edema and reactive/regenerative changes, without eosinophils or evidence of apoptosis, most consistent with nonspecific acute injury.

The patient was placed on a twice daily proton pump inhibitor and underwent repeat endoscopy 5 weeks after initial presentation. At the time of repeat endoscopy, his pain had resolved. His endoscopy was notable for healed duodenal ulcerations with some residual 
duodenal erythema. Repeat biopsies demonstrated normal mucosa without any significant histopathologic changes.

\section{Discussion}

Here, we report the first case, to our knowledge, of duodenal ulceration following HLL. A careful history is helpful in the assessment of whether other exposures could be contributing to the development of PUD in patients without $H$. pylori infection and no or limited NSAID use. Studies from the late 1990s in North America indicated the risk of idiopathic (non-NSAID, nonH. pylori) ulcers to be as high as $20-40 \%[3,4]$. Although these figures may include surreptitious NSAID use, the percentage of idiopathic ulcers has been observed to be rising, including in Asia [5]. Other medications, smoking, illicit drugs such as cocaine, infiltrating diseases (Crohn's disease, sarcoidosis), malignancy, hypersecretory states (gastrinoma, carcinoid syndrome, systemic mastocytosis), and infections (herpes simplex virus, cytomegalovirus) are less common causes of PUD [6].

Gastric and duodenal erosions have been reported following extracorporeal shock wave lithotripsy (ESWL). A prospective study of 40 patients who underwent upper endoscopy before and after treatment with ESWL demonstrated the development of acute gastric and/or duodenal erosions in $32(80 \%)$ of patients [7]. The mechanism of injury was not clear, but the authors speculated that the presence of air in the gastrointestinal tract may have contributed to injury by conducting energy and transmitting it to mucosal surfaces. Animal studies of ESWL have demonstrated extensive lung and large-intestinal damage in rats that were exposed to shock waves in their thoracic and abdominal regions. Complications such as adjacent organ damage, hematoma, and skin bruises have also been reported with ESWL [7]. While the development of gastrointestinal erosions and ulceration has not been reported with HLL, complications such as ureteral perforation, urinary tract infection, ureteral strictures, and renal rupture have been reported [8]. The HLL system operates at a wavelength of 2,100 nm which is strongly absorbed by water and thereby limits the depth of penetration and associated tissue injury as compared to ESWL [9]. However, there is the potential for energy transference to surrounding structures, and the proximity of the retroperitoneal proximal ureters to the retroperitoneal second and third portions of the duodenum suggests that injury to the small bowel could occur, perhaps through damage to microcirculation as a result of extensive HLL. The patient's altered anatomy secondary to his previous surgeries also may have placed these structures closer together in space than is usually observed. In this case, the time course of the patient's symptoms, the endoscopic findings noted, the lack of characteristic histologic findings of NSAID-induced injury (i.e., lack of increased eosinophils or signs of apoptosis), and the lack of other clear contributing factors argue against NSAID injury alone as the cause of his presentation.

In conclusion, here, we present a case of duodenal ulceration following HLL. While H. pylori and NSAID use remain the leading causes of PUD, atypical findings on endoscopy can suggest that additional factors are at play and underscore the importance of obtaining a thorough history regarding additional exposures.

\section{Statement of Ethics}

The authors have no ethical conflicts to disclose. 


\section{Case Reports in Gastroenterology}

\section{Disclosure Statement}

The authors have no conflicts of interests.

\section{Funding Sources}

This study did not have direct funding support.

\section{References}

1 McJunkin B, Sissoko M, Levien J, Upchurch J, Ahmed A. Dramatic decline in prevalence of Helicobacter pylori and peptic ulcer disease in an endoscopy-referral population. Am J Med. 2011 Mar;124(3):260-4.

2 Cai S, García Rodríguez LA, Massó-González EL, Hernández-Díaz S. Uncomplicated peptic ulcer in the UK: trends from 1997 to 2005. Aliment Pharmacol Ther. 2009 Nov;30(10):1039-48.

3 Jyotheeswaran S, Shah AN, Jin HO, Potter GD, Ona FV, Chey WY. Prevalence of Helicobacter pylori in peptic ulcer patients in greater Rochester, NY: is empirical triple therapy justified? Am J Gastroenterol. 1998 Apr;93(4):574-8.

4 Ciociola AA, McSorley DJ, Turner K, Sykes D, Palmer JB. Helicobacter pylori infection rates in duodenal ulcer patients in the United States may be lower than previously estimated. Am J Gastroenterol. 1999 Jul;94(7):1834-40.

5 Chow DK, Sung JJ. Non-NSAID non-H. pylori ulcer disease. Best Pract Res Clin Gastroenterol. 2009;23(1):3-9.

6 Kim HU. Diagnostic and Treatment Approaches for Refractory Peptic Ulcers. Clin Endosc. 2015 Jul;48(4):285-90.

7 Al Karawi MA, Mohamed AR, el-Etaibi KE, Abomelha MS, Seed RF. Extracorporeal shock-wave lithotripsy (ESWL)-induced erosions in upper gastrointestinal tract. Prospective study in 40 patients. Urology. 1987 Sep;30(3):224-7.

8 Chen JS, Chang CC. Renal rupture with perirenal hematoma after ureterorenoscopic holmium:YAG laser lithotripsy for a renal pelvic stone. Urol Sci. 2013;24(3):101-4.

9 Sofer M, Watterson JD, Wollin TA, Nott L, Razvi H, Denstedt JD. Holmium:YAG laser lithotripsy for upper urinary tract calculi in 598 patients. J Urol. 2002 Jan;167(1):31-4.
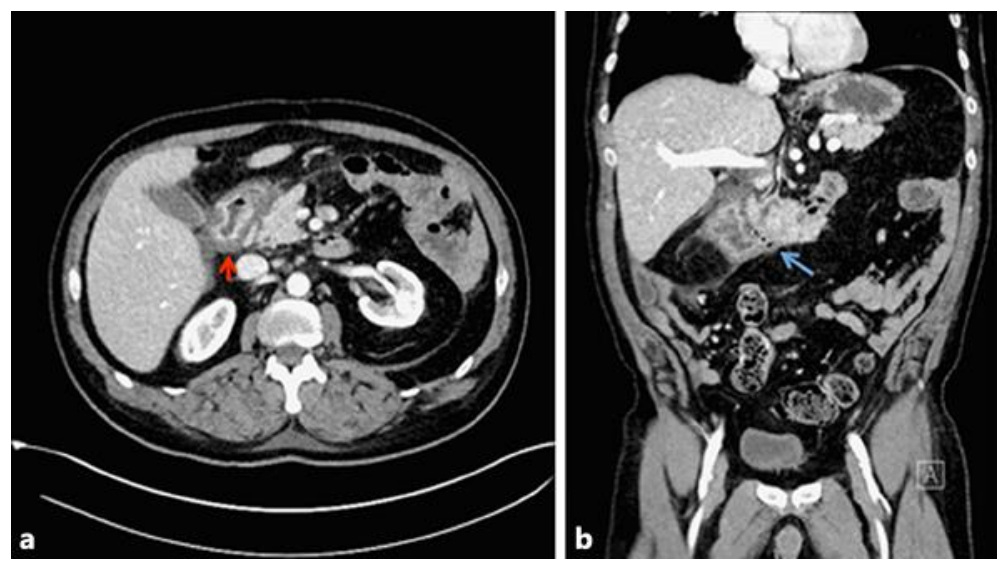

Fig. 1. Axial (a) and coronal (b) views of the CT of the abdomen and pelvis with significant inflammatory changes (red arrow) and intraluminal versus submucosal foci of gas (blue arrow). 


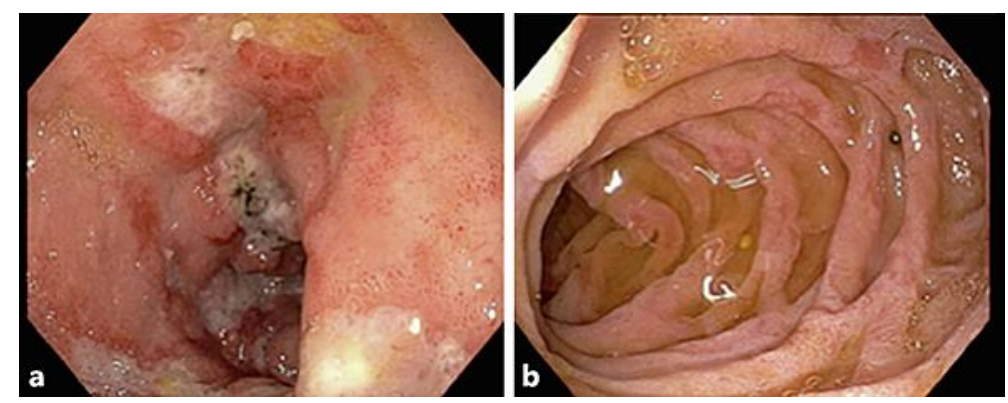

Fig. 2. Endoscopic views of the duodenal bulb (a) and the second portion of the duodenum (b) demonstrating extensive ulcerations with a pigmented spot and erosions. 